\title{
In vitro antioxidant effect of Globularia alypum L. hydromethanolic extract
}

\author{
5. Khlifi, Y. El Hachimi, A. Khalil', N. Es-Safi², A. El Abbouyi
}

\begin{abstract}
Laboratoire de Biochimie Appliquée et Biotechnologie. Faculté des Sciences, EL Jadida, Morocco, ${ }^{1}$ Research Center on Aging, Sherbrooke Geriatric University Institute, University of Sherbrooke, Sherbrooke,

Que., Canada and ${ }^{2}$ Laboratoire de Chimie Organique et d'Etudes Physico-Chimiques, Ecole Normale Supérieure, Rabat, Morocco.

Received: 5.1.2005

Revised: 15.1.2005

Accepted: 22.4.2005

Correspondence to: A El Abbouyi E-mail: elabbouyi@hotmail.com
\end{abstract}

\begin{abstract}
Objective: To investigate the in vitro antioxidant activity of the hydromethanolic extract of aerial parts (leaves and stems) of Globularia alypum L. toward linoleic acid emulsion and human low-density lipoproteins (LDL) peroxidation.

Materials and Methods: Lipid peroxidation was carried out in the presence of G. alypum hydromethanolic extract (10 and $100 \mu \mathrm{g}$ of extract $/ \mathrm{ml})$. CuSO $\mathrm{Cu}_{4}(10 \mu \mathrm{M})$ was used as the oxidation initiator. Conjugated dienes (CD) formation and oxygen consumption were assessed for monitoring the antioxidant properties of the plant extract. Butylated hydroxytoluene at $50 \mu \mathrm{g} / \mathrm{ml}$ was used as standard antioxidant. Quantification of total polyphenolic compounds was carried out according to the Folin-Ciocalteu method.

Results: The hydromethanolic extract of $G$. alypum exhibited significant antioxidant effect. There was a significant inhibition of CD formation in copper ions-mediated linoleic acid emulsion as well as human LDL peroxidation. Analysis of the plant extract revealed a high amount of polyphenols, suggesting a possible role of these compounds in the antioxidant properties.

Conclusion: The obtained results suggested that G. alypum could be a potential source of antioxidants. Further investigations are in progress to determine the active constituent(s).
\end{abstract}

KEY WORDS: Conjugated dienes, linoleic acid, lipid peroxidation.

\section{Introduction}

It is well known that reactive oxygen species (ROS) are involved in many pathological disorders such as atherosclerosis and related cardiovascular diseases, ${ }^{[1]}$ diabetes, ${ }^{[2]}$ and cancer ${ }^{[3]}$ Reactive oxygen species, generated in vivo mainly by neutrophils, macrophages, and xanthine-oxidase system, appear to be responsible in these illnesses by inducing lipid peroxidation via a chain reaction process.

Most living species have protective systems against oxidative stress and toxic effects of ROS. Several studies have demonstrated that the antioxidant properties of plant compounds could be correlated with oxidative stress defense. ${ }^{[4],[5]}$ Thus, antioxidant compounds can be used to counteract oxidative damage by reacting with free radicals, chelating free catalytic metals, and also by acting as oxygen scavengers.

The genus Globularia is commonly used in Moroccan folk medicine. Ethnomedicinal investigations have demonstrated that Globularia alypum, locally named 'Ain Larneb,' is one of the most traditional plant remedies. ${ }^{[6]}$ Its leaves are reported to be used in the treatment of diabetes and in renal and cardiovascular diseases. ${ }^{[6]}$ They are also used as laxative, cholagogue, stomachic, purgative, sudorific, ${ }^{[7]}$ antihypertensive, ${ }^{[8]}$ and hypoglycemic. ${ }^{[9]}$ The involvement of ROS in most of these disorders prompted us to investigate the antioxidant properties of $G$. alypum, which has not been explored until now.

\section{Materials and Methods}

\section{Plant material}

Fresh $G$. alypum L. was collected during spring 2003 from the region of Taza, Morocco. Taxonomic identification was performed by Dr. R. Tellal (Laboratoire d'Ecologie Végétale, Faculté des Sciences. El Jadida, Morocco). A voucher specimen $\left(\mathrm{KS}_{2}\right)$ is kept in the herbarium of the biology department.

\section{Preparation of plant extract}

Fresh aerial parts (stems and leaves) were washed and air-dried in shade at room temperature. They were then mechanically powdered and sieved. One hundred grams of the obtained fine powder was macerated in a hermetically closed glass vessel for $48 \mathrm{~h}$, at room temperature $\left(25^{\circ} \mathrm{C}\right)$, under occasional shaking with $500 \mathrm{ml}$ of a mixture of distilled watermethanol $(3 / 2 \mathrm{v} / \mathrm{v})$. The obtained crude preparation was 
centrifuged at $5000 \mathrm{~g}$ for $45 \mathrm{~min}$ (Sigma 2K15). After filtration, the supernatant filtrate was concentrated under reduced pressure at $25^{\circ} \mathrm{C}$ and the crude extract $(10.75 \mathrm{~g})$ stored at $20^{\circ} \mathrm{C}$ until use.

\section{Chemicals}

Linoleic acid (99\%), ethylenediaminetetra-acetic acid (EDTA), Tween 20 (polyoxyethylenesorbitan monolaurate), butylated hydroxytoluene (BHT) and Folin-Ciocalteu reagents were purchased from Sigma. All other unlabelled chemicals and reagents were of analytical grade.

\section{Isolation of low-density lipoproteins}

Human low-density lipoproteins (LDL) $(1.019<\mathrm{d}<1.063)$ were isolated according to the method of Sattler, ${ }^{[10]}$ using a Beckman Optima TLX ultracentrifuge equipped with a TLA 100.4 rotor, in the presence of EDTA $(0.4 \mathrm{~g} / \mathrm{l})$. After separation, LDL was dialyzed overnight at $4^{\circ} \mathrm{C}$ with $1 / 10^{2} \mathrm{M}$ sodium phosphate buffer (pH 7.0). For oxidation experiments, the LDL dialyzed solutions were adjusted by dilution to $100 \mu \mathrm{g} / \mathrm{ml}$, and proteins were measured by commercial assay (Pierce method, Rockford III, USA).

\section{Measurement of oxygen consumption}

Globularia alypum (Ga) extract (10 and $100 \mu \mathrm{g} / \mathrm{ml})$ was added to $1.5 \mathrm{ml}$ of a $7.5 \mathrm{mM}$ linoleic acid emulsion in $10 \mathrm{mM}$ aqueous phosphate buffer (pH 7.0) and $0.1 \%$ of Tween 20 (v/ v) as emulsifier. The emulsion was air saturated. A freshly prepared solution of $\mathrm{CuSO}_{4}$ was added, at a final concentration of $10 \mu \mathrm{M}$, to initiate the oxidation process. Measurement of the oxygen consumption, according to the modified technique of Genot ${ }^{[11]}$ using Strathkelvin Instruments Oxymeter 949 was started by injection of the sample into a thermostated $\left(25.0 \pm 0.1^{\circ} \mathrm{C}\right) 2 \mathrm{ml}$ measuring cell with no headspace. Oxygen consumption was measured with a Clark electrode and recorded for approximately $25 \mathrm{~min}$ at time intervals of $30 \mathrm{~s}$ with a computer-based data collecting system. The oxymeter was standardized at $0 \%$ of $\mathrm{O}_{2}$ with bisulfite sodium solution $(3.85 \mathrm{M})$ and at $100 \%$ of $\mathrm{O}_{2}$ with air-saturated water solution.

The oxygen consumption rate $V\left(\mathrm{O}_{2}\right)$ in $\mu \mathrm{M} / \mathrm{l} / \mathrm{s}$ was calculated by the following equation:

$$
V\left(\mathrm{O}_{2}\right)=-\frac{\text { Slope } \times\left[\mathrm{O}_{2}\right]_{\text {initial }} \times 10^{6}}{100}
$$

where the slope was calculated from the oxygen consumption curve, $\left[\mathrm{O}_{2}\right]_{\text {initial }}=2.610^{-4} \mathrm{M}$ at $25^{\circ} \mathrm{C}$ Moller. ${ }^{[12]}$

The antioxidant index relative to the rate of oxygen consumption $\left(I_{\text {oxygen }}\right)$ was calculated by the following equation: ${ }^{12]}$

$$
I_{\text {oxygen }}=\frac{V\left(\mathrm{O}_{2}\right)_{\text {sample }}}{V\left(\mathrm{O}_{2}\right)_{\text {control }}}
$$

\section{Measurement of conjugated dienes}

The conjugated dienes (CD) were determined by measuring the absorbance at $234 \mathrm{~nm}$ according to the modified technique described by Esterbauer. ${ }^{[13]}$ Briefly, linoleic acid $(7.5 \mathrm{mM})$ emulsified with Tween $20(0.1 \%$, v/v) or human LDL (100 $\mu \mathrm{g} /$ ml) mixture, in phosphate buffer (pH 7.0, $10 \mathrm{mM})$, was incubated alone (control) or with Ga extract (10 and $100 \mu \mathrm{g} /$ $\mathrm{ml})$. Oxidation was initiated by addition of freshly prepared $\mathrm{CuSO}_{4}(10 \mu \mathrm{M})$ and stopped by cooling in an ice bath in the presence of EDTA $(100 \mu \mathrm{M})$ and BHT $(20 \mu \mathrm{M})$. The absorbance readings were taken every 15 min over $270 \mathrm{~min}$ at $37^{\circ} \mathrm{C}$ in a Beckman UV-Vis spectrophotometer.

The lipid peroxidation kinetic parameters: lag time (min), maximal rate of oxidation $(\mathrm{nM} / \mathrm{min})$, and maximal amount of CD formation $(\mu \mathrm{M})$ were calculated using a molar extinction coefficient of $29500 / \mathrm{M} / \mathrm{cm}$.

The inhibition of linoleic acid and LDL peroxidation was calculated by the following equation:

$$
\% \text { inhibition }=\frac{A_{\mathrm{c}}-A_{\mathrm{s}}}{A_{\mathrm{c}}} \times 100
$$

where $A_{\mathrm{c}}$ is the absorbance of the control reaction and $A_{\mathrm{s}}$ is the absorbance of the treated sample.

Determination of total polyphenolic compounds (PPC)

The amount of total PPC was measured by the method described by Taga ${ }^{[14]}$ using the Folin-Ciocalteu reagent. Briefly, samples and standards were prepared in acidified $(0.3 \% \mathrm{HCl})$ methanol-water solution (60/40 v/v). One hundred microliter of this preparation was added to $2 \mathrm{ml}$ of $0.2 \% \mathrm{Na}_{2} \mathrm{CO}_{3}$. After $2 \mathrm{~min}, 100 \mu \mathrm{l}$ of Folin-Ciocalteu/methanol (v/v) reagent was added to start reaction at room temperature $\left(25^{\circ} \mathrm{C}\right)$ during 30 min. The control mixture consisted of all reagents and solvent without extract. The phenolic concentrations were expressed as phenol equivalent by comparison with a standard calibration curve using phenol solution $(0.01-1 \mathrm{mg} / \mathrm{ml})$.

\section{Statistical analysis}

The results are presented as the mean \pm SD of five replicates. Data were analyzed using one-way analysis of variance (ANOVA) and group means were compared using Duncan's multiple range test. $P$ values $<0.05$ were considered significant.

\section{Results}

\section{Linoleic acid oxidation}

As shown in Figure 1, Ga hydromethanolic extract exhibited a significant inhibition of linoleic acid oxidation as assessed by CD formation. The inhibition extents were $24 \%(P<0.01)$ and $64 \%(P<0.001)$, respectively, at 10 and $100 \mu \mathrm{g} / \mathrm{ml}$, while BHT, used as standard antioxidant at $50 \mu \mathrm{g} / \mathrm{ml}$, gave $76 \%$ $(P<0.001)$.

Figure 1. Effects of Globularia alypum $(\mathrm{Ga})$ hydromethalonic extract on $\mathrm{Cu}$-induced linoleic acid oxidation monitored by conjugated dienes formation. Each point represents the mean of five replicates

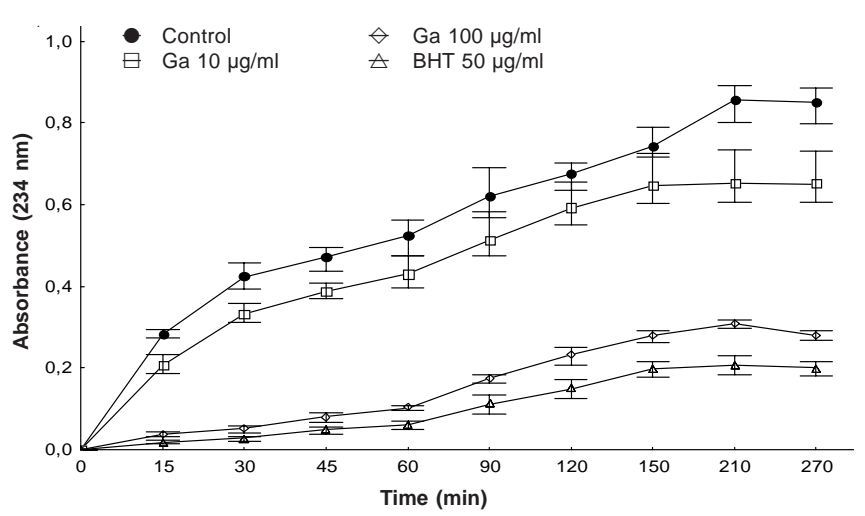


Table 1

Effects of Globularia alypum (Ga) hydromethanolic extract on Cu-induced linoleic acid and human low-density lipoproteins (LDL) peroxidation kinetic parameters monitored by conjugated dienes (CD) formation

\begin{tabular}{|c|c|c|c|c|c|}
\hline Treatment & & Lag phase (min) & Propagation rate (nM/min) & {$[C D]_{\max }(m M)$} & $\%[C D]_{\max }$ inhibition \\
\hline Control & & $0^{\mathrm{a}}$ & $90.1 \pm 3.7^{\mathrm{a}}$ & $29.0 \pm 1.4^{\mathrm{a}}$ & $0^{a}$ \\
\hline Ga $100 \mu \mathrm{g} / \mathrm{ml}$ & & $52 \pm 2.5^{b}$ & $58.8 \pm 2.0^{\mathrm{b}}$ & $10.4 \pm 0.3^{c}$ & $63.9 \pm 0.7^{c}$ \\
\hline BHT $50 \mu \mathrm{g} / \mathrm{ml}$ & & $60 \pm 7.4^{b}$ & $48.6 \pm 2.4^{b}$ & $7.0 \pm 0.6^{d}$ & $75.8 \pm 1.2^{\mathrm{d}}$ \\
\hline One-way & $\mathrm{F}$ & 140 & 27 & 136 & 402 \\
\hline \multicolumn{6}{|l|}{ Human LDL } \\
\hline Control & & $83 \pm 0.8^{a}$ & $62.2 \pm 4.7^{\mathrm{a}}$ & $7.1 \pm 0.2^{\mathrm{a}}$ & $0^{a}$ \\
\hline $\mathrm{Ga} 10 \mu \mathrm{g} / \mathrm{ml}$ & & $140 \pm 2.2^{b}$ & $23.3 \pm 1.4^{b}$ & $2.8 \pm 0.2^{b}$ & $61.2 \pm 2.6^{\mathrm{b}}$ \\
\hline Ga $100 \mu \mathrm{g} / \mathrm{ml}$ & & $150 \pm 3.6^{c}$ & $12.2 \pm 2.1^{c}$ & $1.2 \pm 0.2^{\mathrm{c}}$ & $83.1 \pm 2.9^{c}$ \\
\hline BHT $50 \mu \mathrm{g} / \mathrm{ml}$ & & $85 \pm 1.6^{\mathrm{a}}$ & $46.7 \pm 1.4^{\mathrm{d}}$ & $2.5 \pm 0.3^{b}$ & $76.9 \pm 1.2^{\mathrm{d}}$ \\
\hline One-way & $\mathrm{F}$ & 486 & 417 & 261 & 700 \\
\hline
\end{tabular}

Each value represents the mean \pm SD of five replicates. $\mathrm{df}=3,16$. Values with different superscripts (a, b, c, and d) differ significantly with each other at $P<0.05$ (Duncan's multiple range test).

\section{Table 2}

Effects of Globularia alypum (Ga) hydromethanolic extract on Cu-induced linoleic acid oxidation parameters assessed by oxygen consumption

\begin{tabular}{|c|c|c|c|}
\hline Treatment & $\%$ oxygen consumption inhibition & Oxygen consumption rate $(n M / I / s)$ & $I_{\text {oxygen }}$ \\
\hline $\mathrm{Ga} 10 \mu \mathrm{g} / \mathrm{ml}$ & $63.4 \pm 1.46^{\mathrm{b}}$ & $63.3 \pm 2.9^{b}$ & $0.36 \pm 0.02^{b}$ \\
\hline BHT $50 \mu \mathrm{g} / \mathrm{ml}$ & $76.6 \pm 1.25^{d}$ & $40.3 \pm 2.4^{d}$ & $0.23 \pm 0.02^{\circ}$ \\
\hline One-way & 1792 & 1493 & 1630 \\
\hline ANOVA & $<0.001$ & $<0.001$ & $<0.001$ \\
\hline
\end{tabular}

Each value represents mean \pm SD of five replicates. d.f. $=3,16$. Values with different superscripts $(\mathrm{a}, \mathrm{b}, \mathrm{c}$, and d) differ significantly at $P<0.05$ (Duncan's multiple range test).

The kinetic parameters of oxidation [Table 1] showed that at a low concentration $(10 \mu \mathrm{g} / \mathrm{ml})$, the plant extract did not influence the lag time and the maximal propagation rate of linoleic acid oxidation, but induced a low and significant reduction $(24 \%)(P<0.05)$ in the maximal amount of $\mathrm{CD}$ formation. At a high concentration $(100 \mu \mathrm{g} / \mathrm{ml})$, the extract caused a mean increase in lag time of $52 \pm 2.5(P<0.001)$ and inhibited both propagation rate $(35 \%, P<0.001)$ and maximal amount of CD formation $(64 \%, P<0.001)$.

The antioxidant properties of $G$. alypum were also demonstrated by the oxygen consumption method where the plant extract induced significant effect [Figure 2]. Thus, the Ga extract (10 and $100 \mu \mathrm{g} / \mathrm{ml}$ ) reduced the rate of oxygen consumption by $63 \%(P<0.001)$ and $84 \%(P<0.001)$, respectively. It must be noted that the effect observed with a concentration of $100 \mu \mathrm{g} / \mathrm{ml}$ was more efficient than that obtained with BHT at $50 \mu \mathrm{g} / \mathrm{ml}(77 \%, P<0.001)$ [Table 2].

Human LDL peroxidation

In order to confirm the protective action of Ga extract on
Figure 2. Effects of Globularia alypum (Ga) hydromethalonic extract on $\mathrm{Cu}$-induced linoleic acid oxidation assessed by oxygen consumption (\%). Each point represents the mean of five replicates

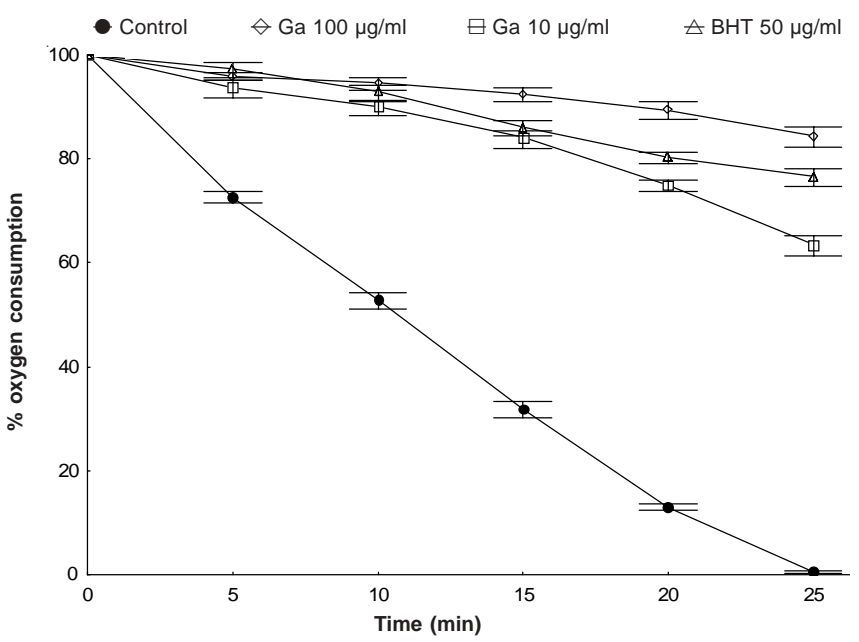


Figure 3. Effects of Globularia alypum (Ga) hydromethalonic extract on $\mathrm{Cu}$-induced human low-density lipoproteins (LDL) peroxidation quantified by conjugated dienes formation. Each point represents the mean of five replicates

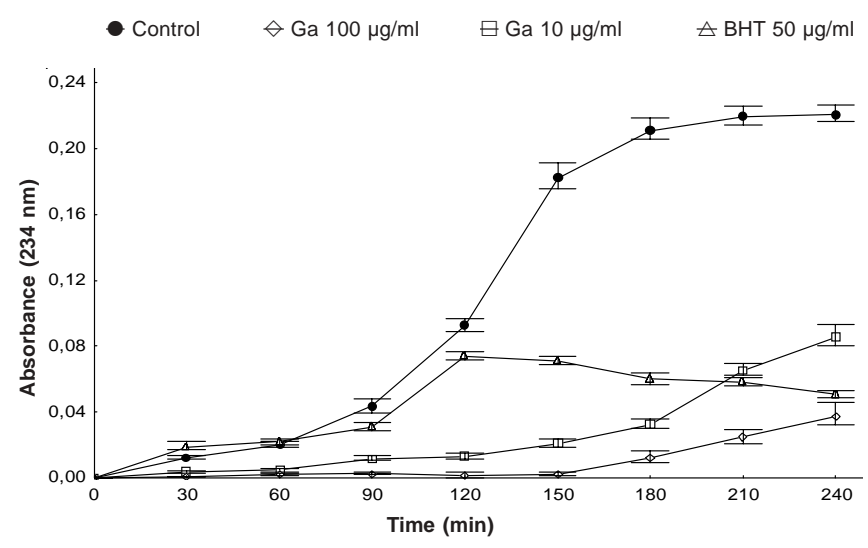

linoleic acid oxidation, we tested its effect on human LDL oxidation by quantifying the CD formation.

The obtained results [Figure 3] showed that copper-induced LDL peroxidation was significantly inhibited by Ga extract. The extent of inhibition of CD formation was $61 \%$, $(P<0.001)$, 83\% $(P<0.001)$ and 76\% $(P<0.001)$, respectively, at 10 and $100 \mu \mathrm{g} / \mathrm{ml}$ of plant extract and BHT at $50 \mu \mathrm{g} / \mathrm{ml}$.

The effects on kinetic parameters showed that the plant extract prolonged the lag time, diminished the propagation rate, and inhibited the maximal amount of CD formation [Table 1]. Standard antioxidant BHT $(50 \mu \mathrm{g} / \mathrm{ml})$ did not affect the lag time but inhibited to a lesser extent the propagation rate and the maximal amount of CD formation.

\section{Discussion}

The present investigation carried out on the antioxidant properties of hydromethanolic extract of $G$. alypum clearly showed the protective activity on lipid peroxidation. However, as previously described, ${ }^{[15],[16]}$ the efficiency of antioxidant activity was dependant on the used lipid system and the method of assessment.

Globally, in the presence of linoleic acid (simple lipid system), the antioxidant effect produced by the extract was lesser or higher than BHT, respectively, when assessed by CD formation or oxygen consumption. According to the kinetic parameters of linoleic acid oxidation, the plant extract (100 $\mu \mathrm{g} / \mathrm{ml}$ ) extended the lag time probably by increasing the initiation stage of the chain reaction. The plant extract also inhibited both the propagation rate and the maximal amount of CD formation.

After the CD formation, one of the first events of lipid peroxidation was the uptake of oxygen and formation of lipid peroxides. ${ }^{[17]}$ In the presence of plant extract, linoleic acid oxidation showed significant decrease in the rate of oxygen uptake, which was higher than that induced by BHT. Probably, the plant extract reacts with peroxyl radicals inducing an inhibition of the lipid peroxidation chain propagation. ${ }^{[16]}$

The antioxidant effect exerted by the plant extract seems to be more efficient in protecting human LDL (complex lipid system) against peroxidation than linoleic acid. The extract increased the lag time and decreased the propagation rate and the maximal amount of CD formation, whereas BHT did not affect the lag phase and weakly decreased the propagation rate. Similar results were obtained with probucol ${ }^{[18]}$ and with a synthesized antioxidant 4GBE43. ${ }^{[19]}$

Otherwise, the high amount of total phenolic content (120 mg of phenol equivalent per gram of extract) led us to suggest that these substances could be responsible of the antioxidant properties of the extract. Polyphenols were reported to have an important role in stabilizing lipid peroxidation $^{[20]}$ and are associated with a wide range of biological activities including antioxidant properties ${ }^{[21-[23]}$ due to their redox properties, as reducing agent or hydrogen atom donors. ${ }^{[4]}$

The implication of the polyphenolic compounds in the antioxidant activity of $G$. alypum is supported by previous results obtained with other Globularia species. Thus phenylethanoid glycosides extracted from Globularia Trichosantha, ${ }^{[24]}$ Globularia davisiana, ${ }^{[25]}$ and Globularitol obtained from Globularia orientalis ${ }^{[26]}$ have been reported to possess scavenging properties.

In conclusion, the protective effect of Ga hydromethanolic extract toward linoleic acid emulsion and human LDL peroxidation was demonstrated by highly significant diminution of both oxygen consumption and CD formation. Further investigations are in progress to characterize the active compounds and to evaluate the usefulness in the treatment of disorders that involve oxidative stress.

\section{References}

1. Pryor WA. Oxidation and atherosclerosis. Free Radic Biol Med2000;28:16812.

2. Sinclair AJ. Free radical mechanisms and vascular complications of diabetes mellitus. Diabetes Res 1993;2:7-10.

3. Pryor WA. Cancer and free radicals. Basic Life Sci 1986;39:45-9.

4. Amarowicz R, Pegg RB, Rahimi-Moghaddam P, Barl B, Weil JA. Free-radical scavenging capacity and antioxidant activity of selected plant species from the Canadian prairies. Food Chem 2004;84:551-62.

5. Aruoma O.I. Methodological considerations for characterizing potential antioxidant actions of bioactive components in plant foods. Mutat Res 2003;5234:9-20

6. Jouad H, Haloui M, Rhiouani H, El Hylali J, Eddouks M. Ethnobotanical survey of medicinal plants used for the treatment of diabetes, cardiac and renal diseases in North centre region of Morocco (Fez-Boulman). J Ethnopharmacol 2001;77:175-82.

7. Bellakhdar J. La pharmacopée marocaine traditionnelle. France: Ibis press; 1997.

8. Ziyyat A, Legssyer H, Mekhfi H, Dassouli A, Serhouchni M, Benjelloun W. Phytotherapy of hypertension and diabetes in oriental Morocco. J Ethnopharmacol 1997;58:45-54.

9. Jouad H, Maghrani M, Eddouks M. Hypoglycaemic effect of Rubus fructicosis $\mathrm{L}$. and Globularia alypum L. in normal and streptozotocin-induced diabetic rats. J Ethnopharmacol 2002;81:351-6.

10. Sattler W, Mohr D, Stocker R. Rapid isolation of lipoproteins and assessment of their peroxidation by high performance chromatography post-column chemiluminescence. Methods in Enzymol 1994;233:469-89.

11. Genot, C, Kansci G, Laroche M. Measurement of phospholipid oxidation in model membranes by determination of oxygen consumption with a semiautomatic polarographic method. Sci des Aliments 1994;14:673-82.

12. Moller JKS, Madsen HL, Aaltonen T, Skibsted LH. Dittany (Origanum dictammus) as a source of water-extractable antioxidants. Food Chem 1999;64:215-19. 
13. Esterbauer H, Streigl G, Puhl H, Rotheneder M. Continuous monitoring of in vitro oxidation of human low density lipoprotein. Free Radic Res Commun 1989;6:67-75.

14. Taga MS, Miller EE, Pratt DE. Chia seeds as a source of natural lipid antioxidant. J Am Oil Chem Soc 1984;61:928-31.

15. Takaya $Y$, Kondo Y, Furukawa T, Niwa M. Antioxidant constituents of Radish Sprout (Kaiware-daikon), Raphanus sativus L. J Agric Food Chem 2003;5:80616.

16. Kulisic T, Radonic A, Katalinic V, Milos M. Use of different methods for testing antioxidative activity of oregano essential oil. Food Chem 2004;85:633-40.

17. Burton GW, Ingold KU. Vitamin E: Application of the principles of physical organic chemistry to the exploration of its structure and function. Acc Chem Res1986;19:194-201.

18. Gotoh N, Shimizu K, Komuro E, Tsuchiya J, Noguchi N, Niki E. Antioxidant activities of probucol against lipid peroxidations. Biochim Biophys Acta 1992;1128:147-54

19. Ezure T, Kanayama T, Nishino C. Action of the novel antioxidants 4 GBE 43 and 2BBE43 against lipid peroxidation. Biochem Pharmacol 2001;62:335-40.
20. Duh PD, Tu YY, Yen GC. Antioxidant activity of water extract of harnjyur (Chrysanthemum morifolium Ramat). Lebensmittel-Wissenschaft und Technologie 1999;32:269-77.

21. Vinson JA, Dabbagh YA, Serry MM, Jang J. Plant flavonoids, especially tea flavonols, are powerful antioxidants using an in vitro oxidation model for heart diseases. J Agric Food Chem 1995;43:2800-2.

22. Roginsky V. Chain-breaking antioxidant activity of natural polyphenols as determined during the chain oxidation of methyl linoleate in Triton $x-100$ micelles. Arch Biochem Biophys 2003;414:261-70.

23. Hou L, Zhou B, Yang L, Liu ZL. Inhibition of human low density lipoprotein oxidation by flavonols and their glycosides. Chem Phys Lipids 2004;129:20919.

24. Çalis I, Kirmizibekmez H, Sticher O. Iridoid glycosides from Globularia trichosantha. J Nat Products 2001;64:60-4.

25. Çalis I, Kirmizibekmez H, Tasdemir D, Ireland CM. Iridoid glycosides from Globularia davisiana. Chem Pharm Bull 2002;50:678-80.

26. Çalis I, Kirmizibekmez H, Tasdemir D, Sticher O, Ireland CM. Sugar esters from Globularia orientalis. Z Naturforsch 2002;57:591-6.

\section{NATIONAL PHARMACOVIGILANCE PROGRAMME Ministry of Health \& Family Welfare}

(Govt. of India)

\section{HELP US ENSURE SAFER MEDICATIONS \\ REPORT ALL ADVERSE DRUG REACTIONS VOLUNTARILY TO YOUR NEAREST ADR MONITORING CENTER}

\section{ZONAL CENTERS}

1. Department of Clinical Pharmacology Seth G.S. Medical College, Mumbai E-mail: dcpkem@vsnl.com

\section{REGIONAL CENTERS}

1. Department of Pharmacology JIPMER, Pondicherry-605 006.

E-mail: pvgjipmer@jipmer.edu

2. Department of Clinical Pharmacology

T.N. Medical College, Mumbai

E-mail: clinpharm@vsnl.com

3. Department of Pharmacology

Indira Gandhi Medical College, Nagpur

E-mail: drmeenashrivastava@rediffmail.com
2. Department of Pharmacology AlIMS

New Delhi

4. Department of Pharmacology IPGMER, Kolkata - 700020.

E-mail: sskm_msvp@yahoo.com

5. Department of Pharmacology Lady Hardinge Medical College, New Delhi 